Session: 2357

\title{
Technology Enhanced Course Material for an Introductory Industrial Engineering Course
}

\author{
Denise F. Jackson, Ph.D., P.E. and Robert Ford, Ph.D. \\ Department of Industrial Engineering, The University of Tennessee
}

\begin{abstract}
The purpose of this paper is to present the initial results of work performed on a grant from the University of Tennessee (UT) College of Engineering (COE). This work focused on the technological enhancement of course material for an introductory industrial engineering (IE) course. This phase provided the first module of a new Web-deliverable learning opportunity for industrial engineering undergraduate students. Through this project, we developed an informational Web site on the fundamental tools and techniques of industrial engineering and their application areas, with details on the interaction of Industrial Engineering with people. The web site currently presents background information, examples, and problems on ergonomics, work measurement, and industrial management. Future developments will include modules on money, computers, equipment, processes, and facilities.
\end{abstract}

\section{Background}

Industrial Engineers, like all engineers, are problem-solvers. The problems our graduates encounter in practice rarely fall neatly into a well-defined category such as manufacturing, facilities design, human factors, quality control, etc; however, we tend to teach problem-solving techniques as if they do. Our graduates need to know not only how to use the tools of our profession, but when to use the most appropriate tools for the particular problem they are attempting to solve. IE majors are introduced to these tools in the IE introductory sophomore course.

Industrial engineering has a broad range of applications, in a variety of industries. This web-based system allows students to interactively control their learning pace across these application areas, and progress through them at their own pace. The modules integrate multimedia technology such as graphics, animations, and audio to increase the effectiveness of an interactive learning experience. They do not provide an integrated approach; rather, they provide the fundamental approaches that may be applied in a situation that requires knowledge of multiple areas. The integration of the IE tools and techniques to solve multi-faceted problems is part of the ongoing project development. 


\section{Introduction}

In developing the multimedia tutorials, we questioned the advantage gained by computer-aided instruction in relation to the development effort. Though the objective is to convey the content, good presentation is vital to effectively do so. Presentation keeps them glued to the video screen, and the typical sophomore student is accustomed to the flashy, eye-catching video games on the market. Thus, we needed the graphics, animations, video, and sound effects of the multimedia tools to help us do the same. We needed these tools to appeal to those students who "never read the book" because they find textbook learning boring.

We also needed to ensure that we were creating an effective tool for inspiring learning. Effective teaching , as identified by Chickering and Gamson ${ }^{1}$, has seven attributes: 1 . encourages studentfaculty contact; 2 . encourages cooperation among students; 3 . encourages active learning; 4. gives prompt feedback, 5. emphasizes time on task; 6. communicates high expectations and 7. respects diverse talents and ways of learning. Klassen ${ }^{4}$ presented support for the use of technology in satisfying or augmenting these attributes. Thus, the use of technology, particularly multimedia tutorials, in an introductory IE course should enhance the learning environment. The objective was to complement the live lectures and not supplement them, as we saw described in much of the literature - particularly that which described applications in distance education.

In designing the multimedia tutorials, we tried to exploit the latitude that the Internet provides. We used hyperlinks to allow students to control the sequence of concepts presented and the level of detail they wanted to obtain. The desire was to provide enough interaction between the student and the computer so that the students would become engaged in the learning experience and would desire to learn more about each of the concepts until they understood the ideas well enough to apply them as needed.

We found that a great deal of programming is required to make full use of the multimedia tools. Developing graphics, animations, video, and sound consumes a great deal of time, especially for us faculty who are new to this mode of presentation and delivery. As a result, we developed the content, while a graduate student from the College of Education's Department of Instructional Technology, Curriculum, and Evaluation (ITCE) developed the presentation. The ITCE graduate student served as our Instructional Resource Assistant. He was qualified to perform this task because of the courses taken in the design and production of educational and interactive Web sites using advanced software. More specifically, they are trained in the development of effective interactive methods for enhancing teaching and learning supported by the principles of planning, designing, creating, testing, and evaluating. Even with this division of labor for design and development, we spent approximately 10 person-months to create each module that generally contains only two to three hours of instruction. 


\section{The Process}

We followed a structured approach in developing the system. It is a hybrid of the Systems Development Life-cycle (SDLC) followed with information systems development. The sequential phases of Analysis, Design, Development, and Implementation were further defined to fit this system. It consists of the following phases:

Phase 1: Project Planning (Analysis)

Phases 2 and 3: Content Design and Module Design (Design - for each module)

Phases 4 and 5: Module Development and Initial Testing (Development)

Phases 6 and 7: Redesign/Redevelopment and Final Testing (Development)

Phase 8: Implementation

The first phase began January 2002. It involved us finding solutions to the following questions:

1. What are key elements in concept that must be developed

2. Audience (type, numbers)

3. Platform(s): hardware, software

4. Content: text, still figures, graphics, animation, sound, video...

5. Interface: user interaction

6. Interaction architecture: software vs. hardware capabilities

We moved forward with our assigned ITCE graduate student without a definite concept for the overall system and clear delineation of our roles. Thus, much time was lost in "rethinking" the overall system. Without a clear system-wide picture, the picture for the individual modules remained fuzzy.

The next two phases involved the design of the major components. Our objective at this point was to design an interface that provided visual stimulation with a balance of text, graphics, and sound. Other design criteria included consistency across the modules to improve the learning curve and ergonometrical features that supported ease of use. We adopted a structure similar to that of the Oklahoma University's site for Fundamentals of Engineering Exam review. ${ }^{3}$ Specifically, we start with an introduction of the concepts, tools and techniques and progress to examples, followed by problems for practice.

The next phases involved the development, testing, and improvements required before implementation. Specific activities included creation of the pages, acquisition of stills and videos and creation of graphics, animations, sounds; testing by IE graduate students, making needed adjustments, and assembling all of the elements into the final module.

The last phase has not begun. The first module has not yet been packaged for distribution. All of the modules still need to be attached, with appropriate interfaces to make the overall system flow 
smoothly. The support for the ITCE graduate student has ended and we are in the process of finding additional funding to complete this phase for the first module. The desired final product is a single system that is web-based or could be viewed from a CD-ROM or DVD.

\section{Software Used}

Various multimedia development tools and technologies were used. The software programs utilized range from programs like Macromedia Dreamweaver, which was used to create the web pages to advanced programs like Macromedia Director, which was used to build interactivity. The following paragraphs give a brief overview of the packages used and some common terms the students may encounter when they use the review. Table 1 provides a summary of these packages.

\begin{tabular}{|l|l|}
\hline \multicolumn{1}{|c|}{ Software } & \multicolumn{1}{c|}{ Purpose } \\
\hline Macromedia Dreamweaver 4.0 & Web Page Development \\
\hline Macromedia Freehand & Drawing \\
\hline Macromedia Flash & Web 2D Animation/Modeling/Rendering \\
\hline Macromedia Fireworks & Web Graphics \\
\hline Macromedia Director & Simulation/Animation and Authoring \\
\hline Macromedia Sound Forge & Sound Editing \\
\hline Adobe Photoshop & Graphics Editing and Painting \\
\hline Adobe Premiere & Video/Sound Editing \\
\hline MetaCreations Carrara & Advanced Animation \\
\hline
\end{tabular}

Table 1. Summary of Software Used

\section{${ }^{5}$ Macromedia Dreamweaver 4.0}

This software is used in a single integrated environment to create, build, and manage websites and Internet applications. It combines visual layout tools with the rapid web application development features. It allowed us to update and publish content to websites without knowing HTML well. However, HTML was also used as a document layout and hyperlink specification language. It enabled us to define the syntax and placement of special, embedded directions not displayed by the browser and the display of the document contents. It also helped in making documents interactive through connecting hypertext links.

\section{${ }^{5}$ Macromedia Flash 5.0}

Macromedia Flash is a vector graphics editor and an animation tool used for drawing graphics and creating animations in a compact file size. The small file size allows easy and fast 
downloading. Flash also allows the developer to add interactive controls within the animations. The compressed exported Flash files, called shockwave flash files, are then embedded directly into the web page. Flash has been used throughout as one of the main animation tools.

\section{${ }^{5}$ Macromedia Director 8.5}

Macromedia Director is a multimedia-authoring program, which is used to build interactive multimedia simulations. Director has been used to create design applications in the modules. Director files are saved as compiled director Shockwave files that can be viewed and operated from a web browser. Shockwave is a general technology that puts Director, and Flash files on a web page and that enables animation, audio, and interactivity to be added to static Web pages with text and graphics.

\section{Layout of the Modules}

The IE introduction was designed and implemented for Internet access to allow wide use and access. The structure of the modules is the same across the different application areas. The user enters with a "WELCOME" page and then is sent to an "IE Definition" page. From there, the user can navigate through the various applications such as people, money, computers, equipment, processes, and facilities. Under each of these area are at least two specific topics. Within each topic, the user is provided with a description, examples, and problems.

\section{The WELCOME Page}

This opening page, shown in Figure 1, is the first page in the system. The user is greeted with music and a spinning globe. The word WELCOME spins around the globe and increases in size. When it stops, the user is sent to the IE Definition page, shown in Figure 2, after 10 seconds.

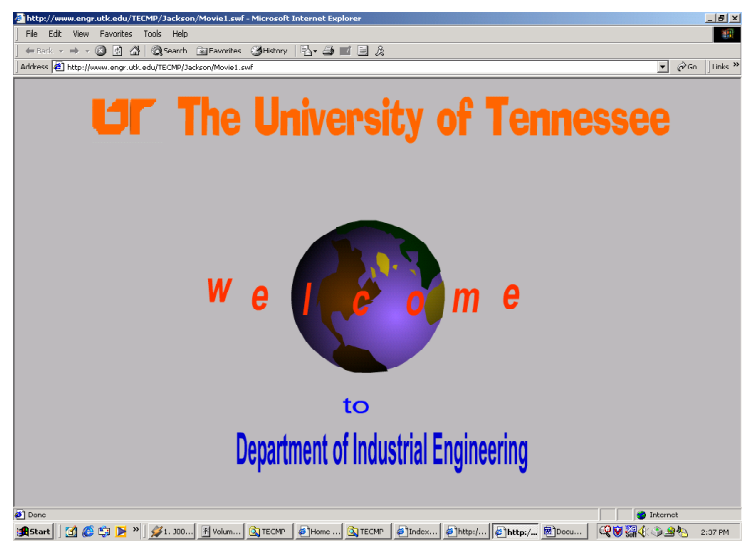

Figure 1. Welcome Page Screen

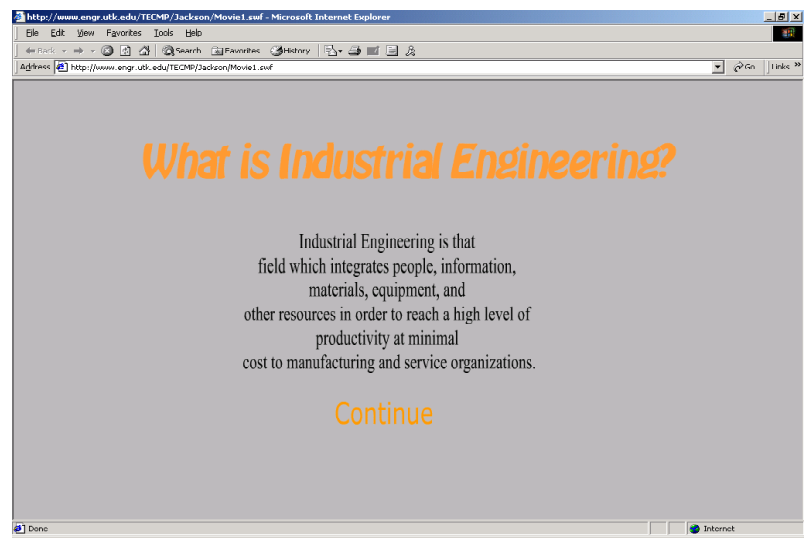

Figure 2. IE Definition Page Screen 


\section{The IE Definition Page}

This page is the second page in the system. The user is provided the IIE definition of Industrial Engineering $^{2}$ that emphasizes that the IE is a systems integrator. This page remains on the screen until the user hits "Continue".

\section{The IE Topics Page}

This next page comes up with circles of graphics depicting six areas under which specific topics have been grouped. These circles dissolve into a text network. The user then selects one of the topics for further investigation. The groupings are subjective and other authors might have combined them differently. This page is shown in Figure3.

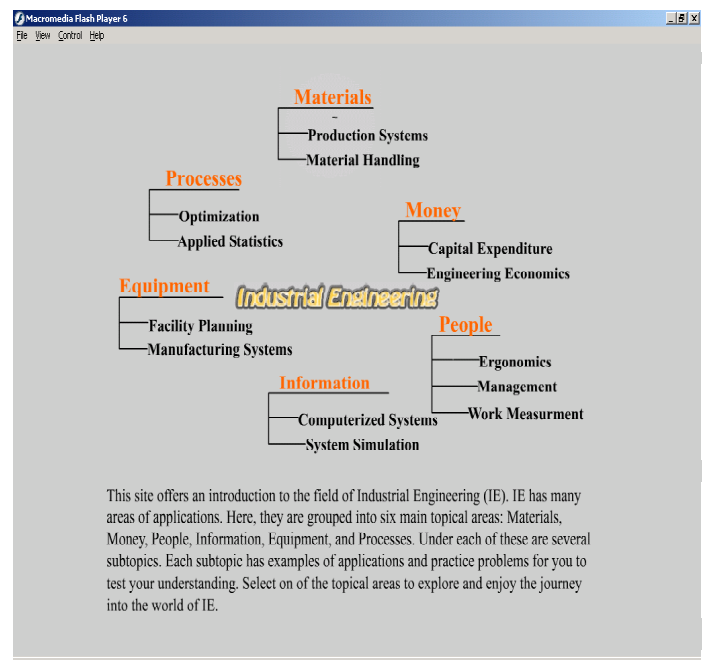

Figure 3. IE Topics Page Screen

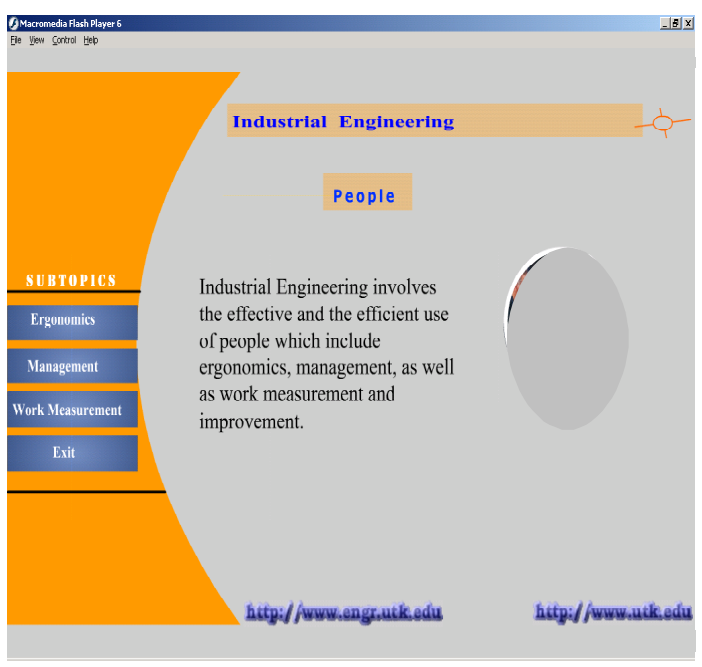

Figure 4.The People Page Screen

\section{The PEOPLE Page and its Topics}

One of the areas is people. That page is shown in Figure 4. On the People page, is a description of the relationship between IEs and the people element of systems. From people, the user may select to go to ergonomics, work measurement, or industrial management. Under each of these topical areas, the user is provided with background information, examples, and problems. 


\section{Conclusions}

This paper presented the initial results for a multimedia, development project that was funded by a grant from the University of Tennessee (UT) College of Engineering (COE). This work focused on the technological enhancement of course material for an introductory industrial engineering (IE) course. One teaching module is completed, and it was described in this paper. Future developments will include modules on money, computers, equipment, processes, and facilities. Additionally, this will be used in the Work Measurement class this fall. With student feedback, we will be able to assess it effectiveness and make improvements.

\section{References}

1. Chickering, A.W., \& Gamson, Z. F. (1987). Seven Principles for good Practice in Undergraduate Education. AAHE Bulletin, 39 (7), 3-7.

2. iienet.org/public/articles/details.cfm?id $=468$

3. eml.ou.edu/fie/home.html

4. Klassen, Johanna, "Pedagogical Support for Use of Information Technology in Teaching", Informing Science: Challenges to Informing Clients: A Transdisciplinary Approach June 2001 pp.301-309, Hong Kong: City University of Hong Kong Press

5. Kinkoph, Sherry, et.al., Teach Yourself Visually: Macromedia Web Collection, Hungry Minds, Inc., New York, 2001.

\section{Robert Ford}

Research Assistant Professor

Ph.D., The University of Tennessee

RESEARCH AREAS: Work systems design and improvement PROFESSIONAL AFFILIATIONS \& AWARDS: Member, Human Factors \& Ergonomics Society; Senior Member, Institute of Industrial Engineer; Board of Directors, Society of Work Science; Professional Member, American Society for Engineering Education.

\section{Denise Jackson, P.E.}

Associate Professor

Ph.D., The University of Tennessee

RESEARCH AREAS: Information systems analysis and design; performance measurement PROFESSIONAL AFFILIATIONS \& AWARDS: Outstanding Faculty Advisor, College of Engineering, 1997-98. Institute of Industrial Engineer, Tennessee Quality Award Examiner; Professional Member, American Society for Engineering Education. 